\title{
UV - Induced Mutagenesis in Lactic Acid Bacteria
}

\author{
Alireza Goodarzi \\ "Armbiotechnology" Scientific and Production Center NAS RA, Yerevan, Armenia
}

\section{Email address:}

masivdo@yahoo.com

\section{To cite this article:}

Alireza Goodarzi. UV - Induced Mutagenesis in Lactic Acid Bacteria. International Journal of Genetics and Genomics.

Vol. 4, No. 1, 2016, pp. 1-4. doi: 10.11648/j.ijgg.20160401.11

Received: March 3, 2016; Accepted: March 9, 2016; Published: March 22, 2016

\begin{abstract}
Induced mutagenesis is widely used for selection of microorganisms producing biologically active substances and further improving of their activities. However, it is rarely used toward lactic acid bacteria (LAB) due to their genetic specificity. Determination of LABs sensitivity to UV light and evaluate the effectiveness of UV-induced mutagenesis by positive selection of antibiotic resistant mutants. Bacterial cells grown in LAPTg and NB broth up to late log phase were harvested by centrifugation and resuspended in phosphate buffer ( $\mathrm{pH}$ 6.8) and irradiated by UV (15 w paired lamps) at distance of $30 \mathrm{~cm}$ and plated on LAPTg and NB agars with and without antibiotics for survivors count and positive selection of Rif and Str colonies. It was revealed that lactic acid bacteria were 1 to $2 \log$ more resistant to UV in compression with E. coli. At dose 40 sec the difference in survival between L. lactis and E. coli was not so significant. The yield of rifampicin and streptomycin resistant mutants of LABs vary depending of UV exposure. The maximum yield about 2-3 log of both types of resistant mutants in lactobacilli and lactococcus were observed at dose $20 \mathrm{sec}(0.1 \%$ survival). LAB possesses intrinsic resistance to UV irradiation $1-2 \log$ higher than E. coli. The maximum yield of UV induced Rif and Str mutants in all LABs occurs at survival about $0.1 \%$. Thus UV rays as an effective mutagen can be used in selection of dairy starters with improved technological and probiotics characteristic.
\end{abstract}

Keywords: Lactic Acid Bacteria, UV Sensitivity, UV-Induced Mutagenesis, Rif and Str Mutants

\section{Introduction}

Lactic acid bacteria (LAB) species are indigenous to food-related habitats, including plant (fruits, vegetables, and cereal grains) and milk environments. In addition, LABs are naturally commensal in small intestine, colon and vagina of human and animals. Efforts are still ongoing to improve technological characteristic of dairy food starters, to amend texture and flavor of fermented dairy food and enhance the probiotic and adaptive properties of $\mathrm{LAB}$ pharmaceuticals and nutraceuticals [1-5].

Traditional genetic methods for selection mutant LABs by use of physical and chemical mutagens are not widely used because of specify their genomes. Comparative genomics has already revealed important similarities and differences in strains, species, and genera and will likely identify key genetic features responsible for the beneficial properties ascribed to probiotic lactic acid bacteria. LAB couldn't synthesize numerous amino acids and nucleotides, due to loss and mutations in their biosynthetic genes. Their requirement in growth factors is higher than human or animals. Beyond gene loss, Lactobacillales have clear ancestral adaptations for nutritionally rich, microaerophilic environments, which include acquisition via horizontal gene transfer and duplication of genes for various enzymes and transporters of sugar and amino acid metabolism [1-6].

Induced mutagenesis is widely used for selection of microorganisms producing biologically active substances and further improving of their activities. However, it is rarely used toward lactic acid bacteria [7]. The N-Methyl-N'-nitro-N-nitrosoguanidine (NTG) induced mutagenesis was used to increase of yields of streptomycin and rifampicin resistant mutant starters with improved technological and organoleptic characteristics in $L$. acidophilus [8]. The mechanism of UV induced mutagenesis of LAB is purely investigated. There are a few publications of use UV light for random selection of LAB mutants among irradiated population of survived microbes [9-13]. Antibiotics enable direct selection of resistant mutants, which suit for evolution of UV light mutagenic efficiency. Earlier Rodriguez-Quinones et al. [14] developed optimal conditions for mutagenesis by NTG in L. plantarum to increase the yield of streptomycin resistant mutant. 
The aim of this study is to determine the sensitivity to UV light and to evaluate the effectiveness of UV-induced mutagenesis in lactic acid bacteria by positive selection of antibiotic resistant mutants.

\section{Material and Methods}

\subsection{Microorganisms}

The lactic acid bacteria Lactobacillus acidophilus GH 201, Lactobacillus delbrueckii MH10 and Lactococcus lactis GH 204 and Escherichia coli K-12 obtained from the Microbial Depository Center of NAS RA.

\subsection{Media}

LAPTg [8] and Nutrient broth (Sigma and agar media were used).

Phosphate buffer solution (PBS) $(0.1 \mathrm{M}), \mathrm{pH} 6.8$ was used in irradiation experiments [15].

\subsection{Ultraviolet Sensitivity Assay}

For ultraviolet sensitivity assay, LAB were grown at $37^{\circ} \mathrm{C}$ in $20 \mathrm{ml}$ of LAPTg and $E$. coli in NB up to OD $0.4(600 \mathrm{~nm})$. The cells were harvested by centrifugation at $5.000 \mathrm{~g}$ for 15 min and washed twice in $20 \mathrm{ml}$ cold PBS. Aliquots of cell suspensions $(2 \mathrm{ml})$ was transferred to sterile Petri dishes $(\mathrm{D}=5$ $\mathrm{cm})$ and exposed to UV-light $(254 \mathrm{~nm})$ for 5, 10, 20 and 40 seconds. After serial dilution, $0.1 \mathrm{ml}$ cell suspensions from each treatment were spread on LAPTg agar and after growth enumerated cells amount. Cultures in flasks wrapped with aluminum foil and plates were kept in complete darkness to avoid photo-reactivation.

\subsection{Mutagenesis and Selection of Antibiotic Resistant Mutants}

LABs were grown at $37^{\circ} \mathrm{C}$ in LAPTg to optical density up to OD 0.6 , cells were harvested by centrifugation at 5,000 $\mathrm{x} \mathrm{g}$ for $15 \mathrm{~min}$ and resuspended in PBS. Cell suspensions $2 \mathrm{ml}$ aliquots were poured in sterile petri dishes and irradiated with UV - light $(254 \mathrm{~nm})$ for 5, 10, 20 and $40 \mathrm{sec}$. Treated cells were diluted tenfold into fresh LAPTg broth and grown at $37^{\circ} \mathrm{C}$ for $4 \mathrm{~h}$ to permit $3-4$ division cycles and spreated on LAPTg agar containing $100 \mu \mathrm{g} / \mathrm{ml}$ of appropriate antibiotic and incubated at $37^{\circ} \mathrm{C}$ till colonies appearance.

\subsection{Statistical Analysis}

Statistical analysis was performed with Student's $t$-test and $P<0.05$ was considered significant to indicate difference.

\section{Results}

The LAB species L. acidophilus, L. delbrueckii, L. lactis and $E$. coli K-12 exposed to UV light $(5 \mathrm{sec}, 10 \mathrm{sec}, 20 \mathrm{sec}$ and $40 \mathrm{sec}$ ) and survival curves were generated to estimate their relative sensitivity (Figure 1)

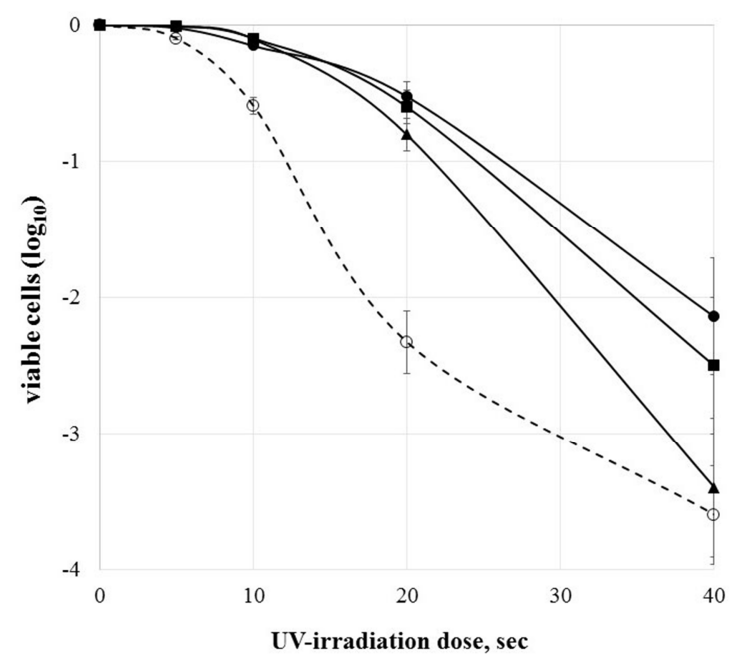

Fig. 1. Survival rate of lactic acid bacteria and E. coli irradiated by UV light.

- - L. acidophilus GH 201, 匹 - L. delbrueckii MH10, $\boldsymbol{\Delta}$ - L. lactis GH 204 and o- E. coli K-12

Figure 1 shows the relative rate of survival of the lactic acid bacteria exposed to UV compared to those of E. coli K-12. The survival curves show that there was steady decrease in survival with increasing exposure to UV. The characters of survival curves of LAB strains as well as E. coli were sigmoidal. The lactic acid bacteria were $1-2 \log$ more resistant to UV than $E$. coli, but at dose $40 \mathrm{sec}$ the difference in survival between L. lactis and E. coli was not so significant.

In order to study UV mutagenicity, rifampicin and streptomycin were used as selective agents for these experiments because of relatively low frequency of their spontaneous resistance mutations $[8,14]$. The mutation rates were derived after plating UV irradiated cultures LAPTg medium with antibiotic.

The yield of Rif and Str mutants of LABs after various UV exposures was studied (Figure 2-3).

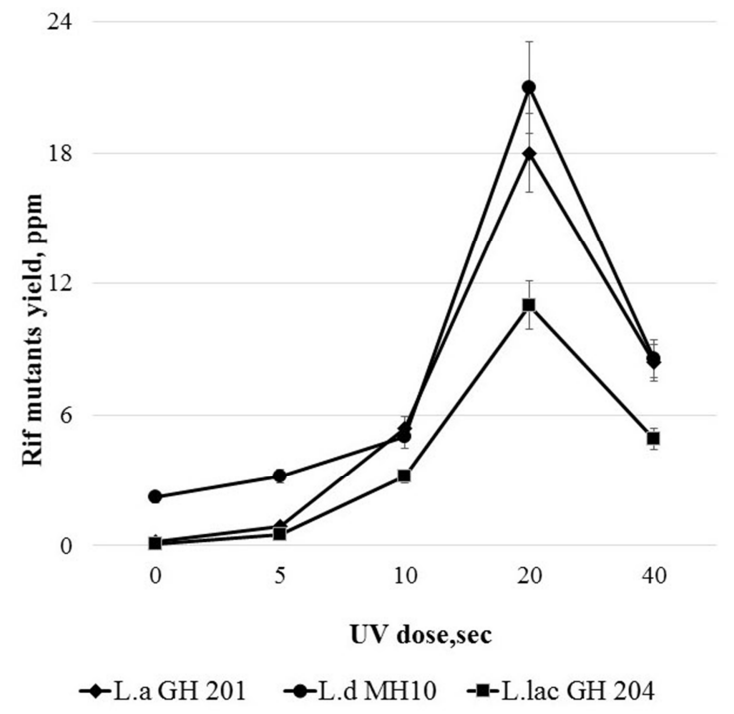

Fig. 2. The yield of Rif mutants of L. acidophilus GH 201, L. delbrueckii MH10, L. lactis GH 204 treated by UV irradiation. 


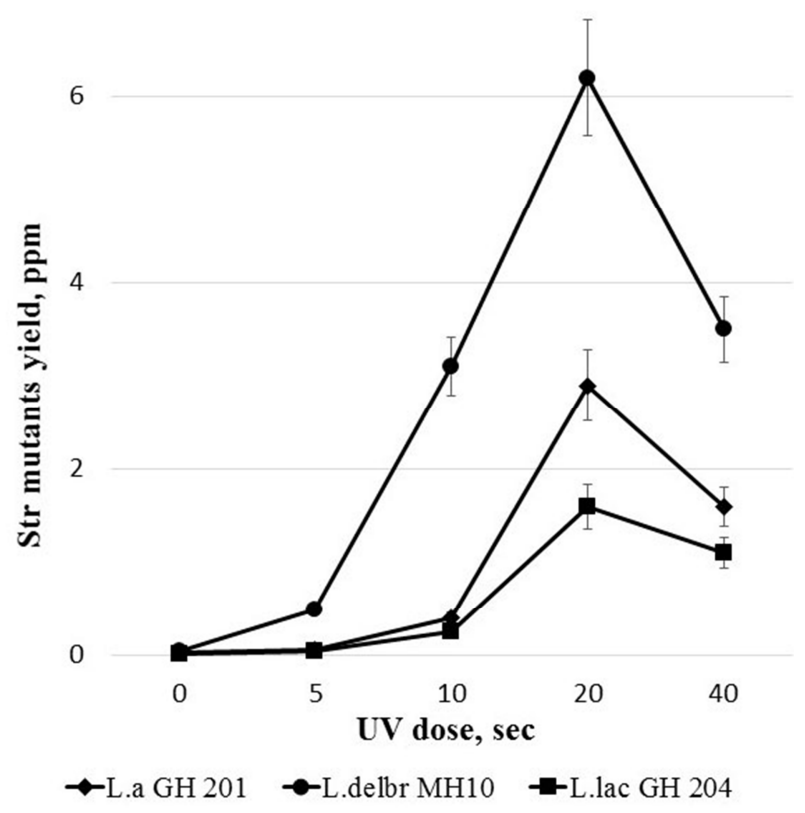

Fig. 3. The yield of Str mutants of L. acidophilus GH 201, L. delbrueckii MH10, L. Lactis GH 204 treated by UV irradiation.

As the LABs survival rate reduced the mutation rate gradually increased, reaches to maximum at dose of $20 \mathrm{sec}$ ( $\sim 0.1 \%$ of survivors). The UV induced yield of Rif and Str mutants were 1-2 log higher than of spontaneous yield. The yield of mutants in the lactobacilli cultures were 1.5 time superior the yield of mutants in L. lactis GH 204. In turn the yield of Rif mutants more than 5 time greater, than Str mutants. All obtained by UV mutagenesis Rif and Str mutants were stable during serial cultivations.

\section{Discussion}

It was revealed that $\mathrm{LABs}$ are 1-2 log more resistant to UV irradiation in comparison with $E$. coli.

UV light causing damages in DNA by formation of covalent bonds (dimer) between neighbors pyrimidines, mainly between thymine $>85 \%$ [16-18]. It could be assumed that the low $\mathrm{G}+\mathrm{C}$ content in LAB (L. acidophilus - 34-37, L. delbrueckii - 49-51 and L. lactis - 34.4-36.3 mol \%) means a high content of $\mathrm{A}+\mathrm{T}$ increases the likelihood of $\mathrm{UV}$ induced thymine dimers formation [1-3]. Despite of this LABs were more resistant in comparison to $E$. coli having about equally ratio of purines and pyrimidines. It might be explained by small size of LABs genomes $(2.0-2.3 \mathrm{Mb})$, the main target of UV rays. Beside of resistance to UV some of lactobacilli show enhanced stress resistance caused by absence of genes for sporulation, catalase, and other key enzymes of oxidative stress response (e.g., superoxide dismutase) [2]. Also LAB high resistance was demonstrated by the increased recovery of live lactobacilli from irradiated food by comparison to staphylococcal and Salmonella species [19]. The intrinsic resistance of $\mathrm{LAB}$ to chemical mutagens such as N-Methyl-N'-nitro-N-nitrosoguanidine (NG) is also significantly higher than $E$. coli $[8,14]$.

The UV induced and spontaneous yields of Rif and Str mutants in LAB were also 1-2 log higher than in E. coli and other bacterial species [20-23]. Despite of difference in sensivity the maximum yield of UV induced Rif and Str mutants in LABs and E.coli were revealed at survival about $0.1 \%$ [15]. The higher frequency of rif mutation related to str mutations can be interpreted by higher content and paradigm of ribosomal genes (e.g. $16 \mathrm{~S}$ DNA, etc.) [1-6].

\section{Conclusion}

LAB possesses intrinsic resistance to UV irradiation 1-2 log higher than E. coli.

The maximum yield of UV induced Rif and Str mutants in all LABs occurs at survival about $0.1 \%$.

Thus UV rays as an effective mutagen can be used in selection of dairy starters with improved technological and probiotics characteristic.

\section{References}

[1] Klaenhammer T. R (1995) Genetics of intestinal lactobacilli. Int Dairy J 5: 1019-1058.

[2] Makarova K, Slesarev A, Wolf Y, et al (2006) Comparative genomics of the lactic acid bacteria. Proc Natl Acad Sci USA 103: 15611-15616.

[3] Schroeter J. D, Klaenhammer T.R (2009) Genomics of lactic acid bacteria. FEMS Microbiol Lett 292: 1-6.

[4] Lebeer S, Vanderleyden J, Keersmaecker S. De (2008) Genes and Molecules of Lactobacilli Supporting Probiotic Action, Microbiol. Mol. Biol. Rev 72 (4): 728-764.

[5] Derkx P., Janzen T, Sørensen K. I, Christensen J. E, Lauridsen B.S, Johansen E (2014) The art of strain improvement of industrial lactic acid bacteria without the use of recombinant DNA technology. Microbial Cell Factories, 13 (Suppl 1): 5-13

[6] Pfeiler E. A, Klaenhammer T. R (2007) The genomics of lactic acid bacteria. Trends in Microbiol 15: 546-553.

[7] Holander S. K (1992) Genetics improvement of microbial starter culture. Application of Biotechnology to Traditional Fermented Foods. 20-26.

[8] Hovhannisyan H. G, Barseghyan A. A, Grigoryan N. G, Topchyan A.V (2010) Genetic improvement of technological characteristics of startars for fermented milk products. Applied Biochemistry and Microbiology 46(4): 395-399.

[9] Arihara K, Itoh M (2000) UV-induced Lactobacillus gasseri mutants resisting sodium chloride and sodium nitrite for meat fermentation. International Journal of Food Microbiology 56(2-3): 227-230.

[10] Henriksen C. M, Nilsson D (2001) Redirection of pyruvate catabolism in Lactococcus lactis by selection of mutants with additional growth requirements. Appl Microbiol Biotechnol 56: 767-775.

[11] Kuila R. K, Ranganathan B (1977) Ultraviolet light-induced mutants of Streptococcus lactis subspecies diacetylactis with enhanced acid- or flavor producing abilities. J Dairy Sci 61: 379-383. 
[12] Boumerdassi H, Monnet C, Desmazeaud M, Corrieu G (1997) Isolation and Properties of Lactococcus lactis subsp. lactis biovar diacetylactis CNRZ 483 Mutants Producing Diacetyl and Acetoin from Glucose. Applied and Environmental Microbiology 63(6): 2293-2299.

[13] Monnet C, Aymes F, Corrieu G (2000) Diacetyl and a-acetolactate overproduction by Lactococcus lactis subsp. lactis biovar diacetylactis mutants that are deficient in a-acetolactate decarboxylase and have a low lactate dehydrogenase activity. Appl Environ Microbiol 66: 5518-5520.

[14] Rodríguez-Quiñones F, Palomares A.J, Megías M, Ruiz-Berraquero F (1984) The influence of several variables for nitrosoguanidine mutagenesis in Lactobacillus plantarum. Curr Microbiol 10: 137-140.

[15] Miller J.H (1992) Mutagenesis with UV. A Short Course in Bacterial Genetics. Cold Spring Harbour Laboratory Press, New York, 150-156.

[16] Chandrasekhar D, Houten B. V (2000) In vivo formation and repair of cyclobutane pyrimidine dimers and. 6-4 photoproducts measured at the gene and nucleotide level in Escherichia coli. Mutation Research. 450: 19-40.

[17] Witkin E. M (1969) Ultraviolet-induced mutation and DNA repair. Annual Review of Genetics 23: 487-514.
[18] Witkin E. M (1976) Ultraviolet mutagenesis and inducible DNA repair in Escherichia coli. Bateriological Reviews 40(4): 869-907.

[19] Hastings J. W, Holzapfel W. H, Niemand J. G (1986) Radiation Resistance of Lactobacilli Isolated from Radurized Meat Relative to Growth and Environment. Applied and Environmental Microbiology 52(4): 898-90.

[20] Gregory S. T, Cate J. H. D, and Dahlberg A. E (2001) Streptomycin-resistant and streptomycin-dependent mutants of the extreme thermophile Thermus thermophilus. J Mol Biol 309: 333-338.

[21] Kogoma T (1994) Escherichia coli RNA polymerase mutants that enhance or diminish the SOS response constitutively expressed in the absence of RNase HI activity. J Bacteriol 176(5): 1521-1523.

[22] Ding J. J, Carol A. Gross J, Gross D. J (1989) Characterization of the pleiotropic phenotypes of rifampin-resistant rpoB mutants of Escherichia coli. J. Bacteriol 171(9): 5229-5231.

[23] Gorini L (1974) Streptomycin and misreading of the genetic code. In M. Nomura, A. Tissières, and P. Lengyel (ed.), Ribosomes. Cold Spring Harbor Laboratory, Cold Spring Harbor N.Y, 791-803. 